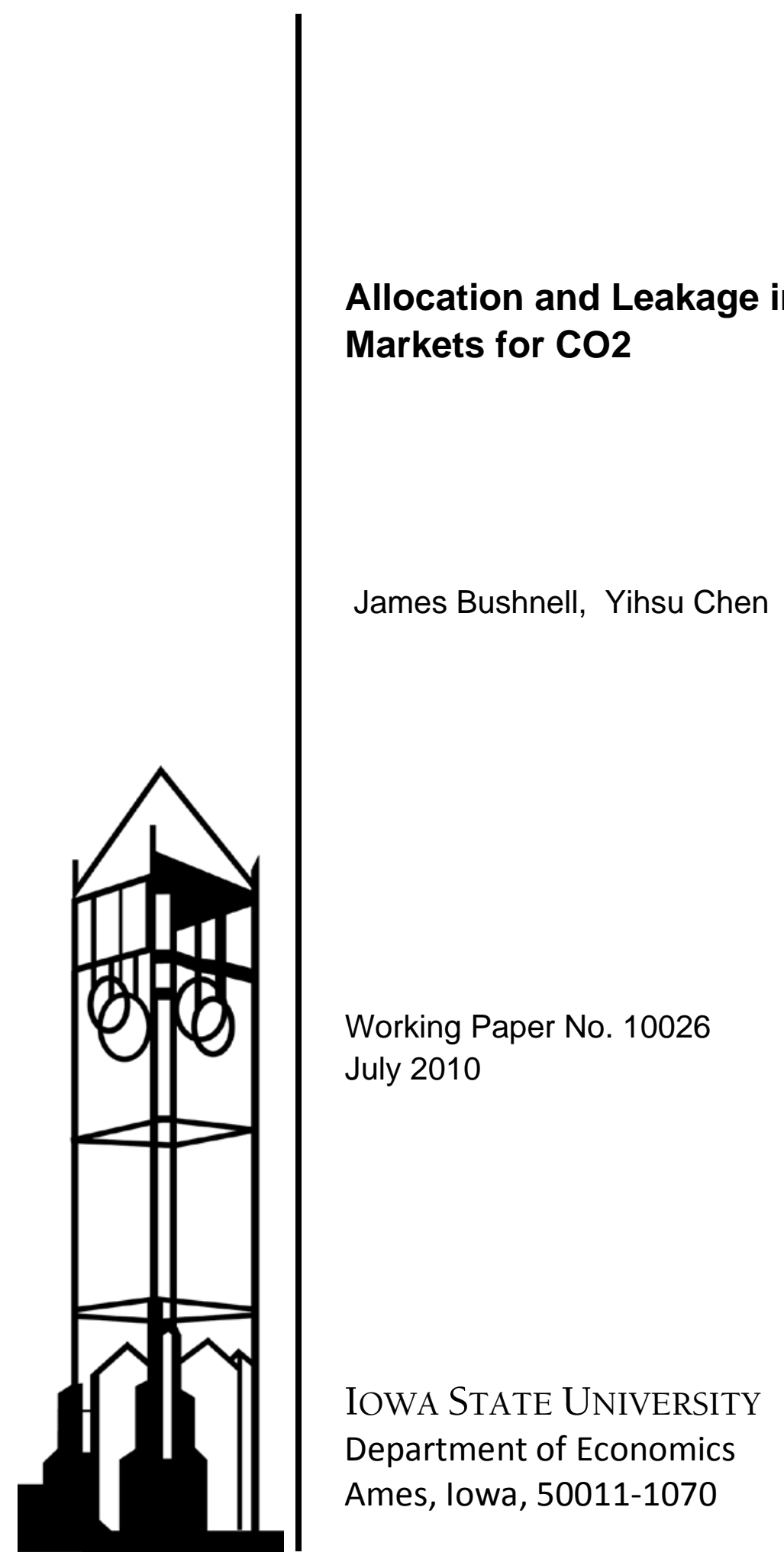

lowa State University does not discriminate on the basis of race, color, age, religion, national origin, sexual orientation, gender identity, sex, marital status, disability, or status as a U.S. veteran. Inquiries can be directed to the Director of Equal Opportunity and Diversity, 3680 Beardshear Hall, (515) 294-7612. 


\title{
Allocation and Leakage in Regional Cap-and-Trade Markets for $\mathrm{CO} 2$
}

\author{
July, 2010
}

\begin{abstract}
The allocation or assignment of emissions allowances is among the most contentious elements of the design of emissions trading systems. Policy-makers usually try to satisfy a range of goals through the allocation process, including easing the transition costs for high-emissions firms, reducing leakage to unregulated regions, and mitigating the impact of the regulations on product prices such as electricity. In this paper we develop a detailed representation of the US western electricity market to assess the potential impacts of various allocation proposals. Several proposals involve the "updating" of allowance allocation, where the allocation is tied to the ongoing output of plants. These allocation proposals are designed with the goals of limiting the pass-through of carbon costs to product prices, mitigating leakage, and of mitigating the costs to high-emissions firms. However, some forms of allocation updating can also inflate allowance prices, thereby limiting the benefits of such schemes to high emissions firms. Thus, the anticipated benefits from allocation updating can be diluted and further distortions introduced into the trading system.
\end{abstract}

(JEL Q50, H23, Q54) 


\section{Introduction}

As climate change policy in the United States struggles to move from concept to implementation, there is increasing focus on the details of its implementation. The concept of capping GHG emissions and allowing trading for compliance remains prominent, although many details about the design of a cap-and-trade system are still hotly debated. Policymakers must often balance equity considerations with the desire to achieve cost-effective and meaningful reductions in emissions. The differential impacts of GHG regulation on various industries, regions, and consumers make the design of those regulations very contentious.

Pending Federal action on climate policy, most of the current initiative has come from the state or regional level in the United States. The Regional Greenhouse Gas Initiative, a cap-and-trade program which covers the electricity sector of the northeastern U.S., began operating in 2009. California's Assembly Bill 32 (AB 32) requires that all sectors of its economy reduce their aggregate GHG emissions to 1990 levels by 2020. The California initiative is proceeding in parallel with the broader-based Western Climate Initiative (WCI). The WCI will establish a regional cap-and-trade program that will initially encompass large stationary sources (primarily electricity) and then expand to include other sources, including transportation fuels in a second phase. ${ }^{1}$

The fact that GHG policy has until recently been driven at the local, rather than national level, has created concern over the geographic limitations of the regulations. Environmental targets can be undermined if production is able to shift away from the jurisdictional reach of the regulator through either leakage or reshuffling of production sources. $^{2}$ These concerns over regional US policies reflect similar, more general concerns with leakage as a challenge even for international climate agreements. In the crafting of European CO2 market, as well as the Waxman-Markey bill that would establish a national cap in the United States, much attention has been paid to the "competitiveness" question, which is fundamentally related to how vulnerable domestic producers are to leakage from imports.

Because of this, a significant fraction of the implementation efforts have been devoted to policies and design choices that can mitigate this leakage problem. The choice of the level of the supply chain at which emissions are measured and regulations applied, known as the "point of regulation," can play a role in limiting the circumvention of the regulations, although previous analysis has argued that these benefits can be overstated and that other efficiency problems can be created. ${ }^{3}$ Here, we focus on the impact of

\footnotetext{
${ }^{1}$ see WCI (2008).

${ }^{2}$ See Bushnell, et. al (2008), Fowlie (2009), and Chen (2009).

${ }^{3}$ See the recommendations of the Market Advisory Committee to the California Air Resources Board
} 
alternative allocation proposals on market performance. This question is also relevant at the international level as current proposals for a US cap-and-trade rely heavily upon allocation mechanisms to blunt the impact of the regulation on competitive trade-exposed industries.

In this paper, we develop a detailed model of the power sector in the western United States, and examine the impacts of alternative cap-and-trade designs on the operations, emissions, and prices in this region. Our research is motivated by several important economic and policy questions relating to cap-and-trade design. First, there is the practical question of just how severe leakage can be in regional electricity markets where only some member states regulate CO2. Obviously the more states that participate, the less severe the potential for leakage may be, but we hope to quantify those risks by examining the benefits of expansion from California to the rest of the WCI. Second, we focus on current policy debates over cap-and-trade design to examine the general relationships between specific design elements and market outcomes such as leakage and overall market efficiency. Specifically, we focus on the question of the allocation of allowances through "updating," a policy that links allocation to ongoing production. This approach appears in various forms in every major CO2 market under consideration. Last, we provide some quantitative, but necessarily qualified, estimates of the impacts of cap-and-trade on allowance and power prices in the western U.S.

We find that leakage of electricity production to unregulated regions is a significant concern, even under the expanded WCI program. One of the key design elements under consideration is the allocation of emissions allowances through updating. The environmental economics literature often focuses on "output-based" updating, which ties allocation of allowances to quantities of product produced. Our results show that output-based updating substantially reduces leakage, and produces relatively low electricity prices compared to an exogenous form of allocation, such as auctioning. Much of the allocation seen in practice, however, either explicitly or implicitly benchmarks the output-based allocations to the emissions intensity of an industry or group of firms. Further when an output-based allocation is applied to multiple industries, it is common to normalize output-based allocations according to an industry standard benchmark of the carbon intensity of production. This approach plays a prominent role in recent U.S. legislative proposals for capping GHG emissions. ${ }^{4}$ While an obvious metric for comparing output across industries, by normalizing allocations according to emissions intensity output-based updating can take on characteristics of emissions-based updating. In the western electricity context, benchmarking has drawn supporters because of the view that

(2007), Burtraw (2008), Chen, et al., (2010).

${ }^{4}$ Both the American Clean Energy and Security Act (H.R. 2454) and the American Power Act ("Kerry-Lieberman") emphasize output-based updating for allocation to energy intensive and trade exposed industries. 
it can help ease the transition to carbon regulation by allocating disproportionately more allowances to relatively high carbon producers, as well as limit the allowance windfall that may be reaped by a low carbon producer under a purely output-based scheme. However as we demonstrate in the context of the WCI market, benchmarking, or equivalently, "fuel-based" updating in fact reverses some of the effects seen under output-based updating. One implication of these results is that, while updating is in part motivated by a desire to provide financial relief to carbon intensive firms, it can in fact leave high polluting firms only modestly better off than if all the allowances were auctioned. At the same time, updating can introduce significant distortions into the abatement decisions of firms and industries.

\section{Design and Modeling of Cap-and-Trade Markets}

As is necessarily the case with markets that are created by regulatory fiat, the choices made by regulators in designing those markets go a long way toward influencing their outcomes. This is certainly true in the case of cap-and-trade (C\&T) markets for the trading of emissions compliance obligations. Such markets exist because regulators create a form of property right, emissions allowances, and induce a demand for those allowances through the setting of the emissions cap. Not surprisingly, the distribution or allocation of those valuable allowances is often a source of great contention. ${ }^{5}$

Traditionally, the allocation of allowences has been held to be an issue limited to economic transfers that need not affect the efficiency of the resulting emissions trading market. Certainly it is the equity concerns that dominate the discussions and debates amongst policymakers and the affected industries. The impacts on efficiency can be negligible if the allocation is truly exogenous to the ongoing operations of the industries subject to the emissions cap, as is the case with the US SO2 trading program (Ellerman, et al., 2000). However, in many cases the allocation of emissions allowances has either been endogenous, or contingent upon market outcomes.

One proposal that has been of increasing interest is to allocate emissions allowances using output-based updating. Under output-based updating each firm receives an allocation of emissions allowances that is proportional to its total product production. In the electricity context, for example, this means each firm receives an allocation that is proportional to the MWh generated within the regulatory jurisdiction. ${ }^{6}$ The effects of

\footnotetext{
${ }^{5}$ See, for example Kanter and Mouawad, 2008.

${ }^{6}$ We use the term generated somewhat loosely here, as in the California and WCI context, the point of regulation is mixed. Emissions from sources within the cap-and-trade region will be regulated along the lines of traditional source-based cap-and-trade systems. In additions imports into the cap-and-trade
} 
output-based updating have been a subject of much research. ${ }^{7}$ In general, it is believed that output-based updating would help to mitigate leakage, as firms would be rewarded (in the form of allowances) for domestic production. Output-based updating is also widely believed to result in lower product prices than alternative forms of allocation.

While one strain of the academic literature has focused on the detrimental efficiency effects of such a price impact, it has an appeal to regulators. For example, the design recommendations of both the California Public Utilities Commission and the WCI include the minimization of the impacts of carbon regulations on consumers as a prominent objective of the allocation process. Despite the appeal of the product price effect, these "lower" prices can lead to inefficient over-consumption as the externality cost of the pollution is not reflected in product prices. ${ }^{8}$ It is interesting to note, however, that in a general equilibrium setting, the welfare effects of minimizing the product price impacts are more ambiguous. ${ }^{9}$

Further, there is a concern that output-based updating, if applied symmetrically to all producers (or at least to all fossil-fueled producers), would exacerbate equity concerns. For example, there is a fear that low-carbon producers will experience a "windfall" under output-based allocation, while high-carbon producers will suffer most of the cost impacts of GHG regulations. This is because output-based allocation favors cleaner producers. They are rewarded for production, and penalized for emissions. Traditionally, allocation has been used as a tool to "soften the blow" of increased environmental compliance through allocations based upon historic emissions patterns, also known as grandfathered allocations. Under grandfathered allocation, larger polluters receive a larger share of the allocations, while also paying more for compliance due to their higher emissions levels. In this way the total costs to high-emissions producers are mitigated, while the marginal cost of compliance remains the same. The California Public Utilities Commission has recommended (CPUC, 2008) an alternative we will refer to as "fuel-based" updating in order to address this equity concern. Under fuel-based updating, the allocation of emissions allowances per MWh of generation would be higher for high-carbon (e.g., coal-

region will also be regulated under a system known as the "first-deliverer." In effect the importer of the product will be required to surrender emissions allowances equivalent to the emissions required to produce that product, even though the production itself occurs physically outside of the cap-and-trade region. Under first-deliverer, the importers would also be eligible for allocations under an updating scheme. These allocations would be proportional to the MWh imported into the cap-and-trade region.

${ }^{7}$ see Jensen and Rasmussen (2000), and Fischer and Fox (2007), Fischer (2010)

${ }^{8}$ See Burtraw, Palmer, and Kahn (2005) for a discussion of the various impacts of updating.

${ }^{9}$ This is because the price impacts of the environmental regulation may exacerbate the negative impacts of other existing taxes and regulations. Although there has been considerable focus on using the revenues from environmental regulations to offset these distortions (see Goulder, Parry and Burtraw (1997), and Fullerton and Metcalf (2001)) it is possible that minimizing the price impact on the regulated products could also work in the same direction. 
based) producers than it would be for low-carbon (e.g., gas-based) producers.

Fuel-based updating is part of a general class of allocation approaches that utilize benchmarking at an industry or process level. It is in fact more common than "pure" output-based allocation in practice. This is in part due to the equity concerns described above, and also due to the fact that it is not always easy to either measure or compare the "output" of some plants, particularly in C\&T programs that span multiple industries. Some states participating in the US NOx budget program utilize a form of benchmarking that is based upon the heat-input of power plants. Allocations the ETS market for CO2 in the European Union have contained, at least implicitly, several aspects of updating. (Grubb and Neuhoff, 2006, Ahman, et al., 2006). It is also expected that updating will play a significant role in the emerging US national cap-and-trade legislation.

The analysis of updating proposals has focused on the efficiency implications of these approaches. In addition to inefficient over-consumption, updating can result in a productive inefficiency by distorting relative production decisions, as well as distort long-term investment signals. ${ }^{10}$ Several papers have examined the interaction of allocation policy with leakage and efficiency for specific industries, including electricity (Neuhoff, Martinez, and Sato (2006)) and cement (Demailly and Quirion (2006)).

However, these papers tend not to emphasize the aspects of updating that motivate their application in practice. These are the impacts of updating on allowance and product prices, as well as the equity effects for firms. Using a theoretical model, Bohringer and Lange (2005) consider a "closed" trading system where the cap is fixed and there is no opportunity for trading with other emissions markets. When allocations are exactly proportional (but not equivalent) to emissions, updating recreates the "first-best" product prices and emissions of auctioning. The allowance prices, however, rise in a closed system. This is because emissions-based allocation reduces the perceived marginal rate of emissions for firms. In order to achieve the reductions required by the cap, allowance prices must rise to offset this perceived discounting of emissions rates. Although higher-emissions firms receive larger allocations, they pay disproportionately more for the emissions that are not covered by allocation, due to the higher equilibrium allowance prices. In an "open" trading system, the effect of updating tends to push the abatement to regions or industries that are not receiving the implicit production subsidies in the form of updated allowance allocations.

The western market we examine here has characteristics of both closed and open systems. The allocation rules are aimed at market shares, and therefore the industry level cap would not change with allocation results. In the initial years of the WCI, when the allocated shares will be the largest, emissions will be dominated by the electric

\footnotetext{
${ }^{10}$ See Jensen and Rasmussen (2000), Ahman and Holmstrom (2006), and Sterner and Muller (2008)
} 
sector. As mentioned before, however, leakage is also a concern. There will therefore be opportunities for trading product, if not emissions allowances with neighboring regions. The goal of this paper is to try to sort through these factors and establish the relative impacts of them on market outcomes.

\subsection{Analysis of Cap-and-Trade Design}

For the most part, empirical projections of cap-and-trade markets for GHG have tended to take the "long-view" approach of simulating outcomes 10 to 20 years in the future. The studies commissioned by the regulatory agencies responsible for implementing California's AB 32, for example, emphasize the year 2020 (see discussion of the E3 model in CPUC (2008)). As such this work tends to be focused on the important assumptions one must make about the trajectory of future electricity demand and trends in the investment of new generation technologies. Chen et al. (2008) examine the economic and emissions implications of the three C\&T proposals considered under AB32: source-, load- based and first-seller. When cross-boarder electricity sales are subject to an emissions cap, they show that these three proposals produce the same market outcomes, and all of them are prone to emissions leakage. None of these studies consider how outcomes might change under different allocation schemes.

Because of our focus on the specific design of the cap-and-trade mechanism, and its impact on the operation of electricity markets, we instead take the "near-view" approach. We base our analysis upon actual market data drawn from the year 2007, and look at the counter-factual question of how those markets would have functioned under a cap-and-trade regime. In this sense the work follows in the spirit of Fowlie (2008), who also studies the potential for leakage from a California-only market, and also that of Bushnell, Mansur, and Saravia (2008) who deploy similar techniques to examine competition and vertical contracting issues. In a fashion similar to Schuliken, et al., (2008), we formulate the joint equilibrium outcomes of the emissions and electricity market as a linear-complementarity problem.

Our study differs from previous work in several important ways. While Fowlie and the E3 study employ an empirical model of portions of the western electricity market, we model the emissions allowance prices as endogenous to the cap-and-trade market. This is central to our work given our focus on the endogenous impact of allocation policies on allowance prices. Second, in addition to California's CO2 policies, we examine the broader western market proposed under the WCI. Last, we explicitly consider how allocation policies can affect firm behavior in the western US. Previous work examining the impacts of allocation have either taken a general equilibrium approach (Bohringer 
and Lange (2005), Sterner and Muller (2008), Fischer and Fox (2008), or more complex formulations applied to stylized market data (Shuliken, et al., 2008, Neuhoff, et al., 2006).

We also take a different approach than most similar analyses to developing our market elements used for the simulation. One difficulty with simulating electricity markets in a high level of detail is that, while data on most fossil-fuel based generation units is quite extensive and reliable, there are far less data on the activities of hydro-electric plants, renewable generation, and the substantial amount of power generated from combined heat \& power or "cogeneration" plants. When building a counter-factual recreation of an electricity market, these data gaps make assumptions about the missing production necessary.

We take the approach of restricting our construction of a counter-factual market outcome to the portion of resources for which we do have detailed data. In effect we are assuming that, under our counter-factual, the operations of non-modeled generation plants would not have changed. This is equivalent to assuming that compliance with the carbon reduction goals of a cap-and-trade program will be achieved through the reallocation of production within the set of modeled plants. We believe that this is a reasonable assumption for two reasons. First the vast majority of the carbon emissions from this sector come from these modeled resources. Indeed, data availability is tied to emissions levels since the data are reported through environmental compliance to existing regulations. Second, the total production from "clean" sources is unlikely to change in the short-run. The production of low carbon electricity is driven by natural resource availability (e.g., rain, wind, solar) or, in the case of combined heat and power (CHP), to non-electricity production decisions. The economics of production are such that these sources are already producing all the power they can, even without additional carbon regulation. To a first-order, short-run emissions reductions will have to come either from shifting production from among conventional sources, a reduction in end-use electricity demand, or through substitution with unregulated imports, i.e., leakage or reshuffling. ${ }^{11}$

\section{Model}

In this section, we first describe our equilibrium model and then discuss how we apply data from various sources to arrive at our calculations.

\footnotetext{
${ }^{11}$ It is important to recognize that our modeling approach not only assumes that existing zero-carbon sources will not change how much they produce but also when they produce it. An interesting question is whether a redistribution of hydro-electric power across time could lower carbon emissions by enabling a better management of fossil generation sources. Such an analysis would require a co-optimization of hydro and thermal electric production and is beyond the scope of this paper.
} 
Although this simulation approach is capable of representing imperfect competition in the product market (i.e., electricity) we assume here that firms act in a manner consistent with perfect competition with regards to both the electricity and emissions allowance markets. ${ }^{12}$ We still model these markets as a series of equilibrium conditions for each of the individual firms represented, as the incentive effects on individual firms from policies such as updating are still relevant here.

The key variables and parameters of the model are grouped according to four important indices; the firm, location, technology, and time period of production. The total production of firm $i$ from generation technology $j$, and location $l$ at time $t$ is represented by $q_{j, l, t}^{i}$. Total emissions by firm and technology are denoted $e_{j, l}^{i}\left(q_{j, l, t}^{i}\right)$. We assume that marginal emissions rates can be increasing in quantity $\left(e_{j, l}^{i \prime} \geq 0\right)$, but are unchanging over time. Production $\operatorname{costs} C_{j, l}^{i}\left(q_{j, l, t}^{i}\right)$ vary by firm, technology, and location, and as described below are assumed to be quadratic in output $q_{j, l, t}^{i}$.

For each firm $i \in\{1, \ldots, N\}$ and time period $t \in\{0, \ldots, T\}$, a perfectly competitive, or cost-minimizing firm $i$ maximizes profits for all its technologies $j$ and locations $l$ over periods $0, \ldots, T$ :

$$
\pi_{i}\left(q_{j, l, t}^{i}\right)=\sum_{t} \sum_{l} \sum_{j}\left[p_{l, t} \cdot q_{j, l, t}^{i}-C_{l, j}^{i}\left(q_{j, l, t}^{i}\right)\right] \cdot r^{-t}-\sum_{t} \sum_{l \in R E G} \sum_{j} \lambda_{t} \cdot e_{j, l}^{i}\left(q_{j, l, t}^{i}\right) \cdot r^{-t}
$$

where $r$ is the discount rate and $p_{l, t}$ and $\lambda_{t}$ are the wholesale prices of electricity and $\mathrm{CO} 2$ allowances in period $t$, respectively. Allowance prices are assumed to be uniform across the regulated (capped) region. Wholesale electricity is assumed to be a homogenous commodity for purposes of setting wholesale prices, although prices are assumed to vary by location subject to transmission constraints as described below. However, electricity production falls into two categories, that within the region covered by the emissions cap and that outside the reach of the regulation. The set $R E G$ represents those plants located inside the cap and trade region.

In practice, the above model would be part of a larger multi-period cycle of emissions compliance and allocation. As we describe in section 3.3, the first order conditions of 1 are explicitly related to variables in period $t$ as well as allowance prices in $t+1$. In effect, the allocations are given out at the end of the cycle, just before allowances are required to be surrendered. This suggests that a simplified two-period representation is sufficient

\footnotetext{
${ }^{12}$ Although the California market was notorious for its high degree of market power in the early part of this decade, competitiveness has dramatically improved in the years since the California crisis, while the vast majority of supply in rest of the WECC remains regulated under traditional cost-of-service principles.
} 
to capture the key qualitative impacts of updating on the incentives of firms. ${ }^{13}$ In the following section, we therefore represent the allocation decision as part of a "closed-loop," to a single cap-and-trade compliance cycle by applying the Hotelling rule, which requires allowance prices to grow in commensurate with interest rate. The same approach has also used elsewhere (see Rubin (1996)). These allocations are then linked to the actual output of producers during the compliance cycle that is about to conclude. We therefore suppress the effect of interest rates or other dynamic considerations. In this and other ways, our analysis should be considered a view of the short-run impacts of these policies. It should also be noted that we do not consider the incentives effects on investment in new generation capacity. While these incentives may be important considerations in some context we note that current proposals for updating allocations in California and the WCI are designed to sunset relatively quickly and there are no specific provisions to include new facilities in the updating process. Because of these factors we believe that the short-run incentive effects are likely to dominate long-run effects.

\subsection{Cap-and-Trade Design}

The profit function described in the previous section assumes a standard source-based cap-and-trade market, where the compliance obligation rests explicitly on the producer (in this case the electricity generator). As the focus of C\&T design turned to allocation, however, much of the regulatory emphasis was devoted to mitigating consumer prices, smoothing the cost impacts to firms (at least somewhat), and mitigating the "windfall" profits that might be earned by low-carbon producers (CPUC (2008)). These goals were to be addressed primarily through allocation policies. In particular, two specific alternative implementations of output-based updating are considered here.

\subsubsection{Output-based Updating}

As discussed above, one mechanism that can depress product market prices and at least partially combat leakage is output-based updating. In this context, the allocation of emissions allowances would be tied to the electricity production of firms. Each MWh of production would earn a fraction of an emissions allowance.

Following this assumption, we can rewrite the profit maximization problem for each firm to include the prospect of output-based allocation of emissions allowances. Let $\delta_{t} \cdot q_{j, l, t}^{i}$ be the allocation of emissions allowances earned for use in the compliance cycle

\footnotetext{
${ }^{13}$ See Hagem and Wetskog (2008) apply a similar two-period setting to study cost-effectiveness of intertemporal emissions trading.
} 
$t+1 \ldots T$ from producing $q_{j, l, t}^{i}$ units of electricity in regulated region $l$ during period $t$. Note that we assume that the overall cap does not change from period to period, only that the distribution of (zero-cost) emissions allowances across firms varies with the relative output of firms and their facilities. In other words $\delta_{t}=\tilde{\delta} \frac{C A P}{Q_{t}}$. where $Q_{t}$ is the aggregate production (market demand) in period $t, \tilde{\delta}$ is the overall fraction of allowances that are allocated through updating, and $t \in 0 \ldots T$ is the cycle of the compliance period. Thus, the program of output-based updating would not take the form of a "tradable performance standard." 14 Under a performance standard, the subsidy for output is not limited by an overall cap. Even if the performance standard were a regulatory mandate, rather than an allocation of emissions allowances, there is an implicit subsidy of production. Compliance with a mandate, when specified as an intensity per unit of output, can be advanced both through limiting the undesirable input and expanding total output. ${ }^{15}$

The profit for firm $i$ will now include consideration of the additional allowances earned from additional production:

$$
\pi_{i, t}\left(q_{j, l, t}^{i}\right)=\sum_{l} \sum_{j}\left[p_{l, t} \cdot q_{j, l, t}^{i}-C_{l, j}^{i}\left(q_{j, l, t}^{i}\right)\right]-\sum_{l \in R E G} \sum_{j}\left[\lambda_{t} \cdot e_{j, l}^{i}\left(q_{j, l, t}^{i}\right)-\frac{\lambda_{t+1}}{r} \cdot \delta_{t} \cdot q_{j, l, t}^{i}\right] .
$$

This profit equation highlights how the updating weakens the marginal cost impact of the cap-and-trade requirement for a given allowance price, $\lambda_{t+1}$. Equation (2) can then be simplified by $\lambda_{t}=\frac{\lambda_{t+1}}{r}$ when applying the Hotelling rule:

$$
\pi_{i, t}\left(q_{j, l, t}^{i}\right)=\sum_{l} \sum_{j}\left[p_{l, t} \cdot q_{j, l, t}^{i}-C_{l, j}^{i}\left(q_{j, l, t}^{i}\right)\right]-\sum_{l \in R E G} \sum_{j} \lambda_{t}\left[\cdot e_{j, l}^{i}\left(q_{j, l, t}^{i}\right)-\delta_{t} \cdot q_{j, l, t}^{i}\right] .
$$

For facilities with an average emissions rate higher than the allocation rate, the capand-trade still effectively taxes output, although at a lower rate. For facilities with an average emissions rate that is lower than the allocation rate, $\frac{e_{j, l}^{i}\left(q_{j, l, t}^{i}\right)}{q_{j, l, t}^{i}}<\delta_{t}$, there is now a production subsidy.

\subsubsection{Fuel-based Updating}

The other approach to updating under consideration would distinguish between the inputs of various production sources. Motivated by a desire to limit the cost impacts of

\footnotetext{
${ }^{14}$ See Fischer, 2003.

${ }^{15}$ See Fullerton and Heutel (2007). One current proposal that exhibits this characteristic is the "low carbon fuel standard" for transportation fuels (see Holland, Hughes, and Knittel (2008)).
} 
cap-and-trade on utilities heavily reliant on coal-based sources of power, this proposal would allocate emissions allowances to generation from differing fuel sources in a ratio roughly aligned with the average GHG emission rate from each fuel source. In the notation of our model, this approach would provide $\delta_{j, t}$ emissions allowances to each MWh of generation from a source of technology type $j$. In other words, each technology could in theory be subject to a separate allocation ratio. The resulting equilibrium condition for production for firm $i$ would be

$$
\pi_{i, t}\left(q_{j, l, t}^{i}\right)=\sum_{l} \sum_{j}\left[p_{l, t} \cdot q_{j, l, t}^{i}-C_{l, j}^{i}\left(q_{j, l, t}^{i}\right)\right]-\sum_{l \in R E G} \sum_{j}\left[\lambda_{t} \cdot e_{j, l}^{i}\left(q_{j, l, t}^{i}\right)-\frac{\lambda_{t+1}}{r} \cdot \delta_{j, t} \cdot q_{j, l, t}^{i}\right] .
$$

As with the output-based allocation, the allocation component $\delta_{j, t}$ weakens the impact of allowance prices on the perceived marginal cost of production. The strength of this effect is now asymmetric with respect to fuel types, and its net impact will depend upon the specific value of $\delta_{j, t}$. The general intent of the fuel-based updating is to weaken the impact on higher emission technologies and therefore soften the blow of implementing the cap. A somewhat extreme version of this allocation would arise if emissions rates within each technology class were constant and equivalent across all firms and locations (i.e., $e_{j, l}^{i}{ }^{\prime}=\tilde{e}_{j}$ ) and the allocation factors were applied proportionately to emission rates $\delta_{j}=\tilde{\delta} \cdot \tilde{e}_{j}$. If we also assume that the Hotelling rule applies to allowance valuation, and $\lambda_{t}=\frac{\lambda_{t+1}}{r}$, then equation (4) can be rewritten as

$$
\pi_{i, t}\left(q_{j, l, t}^{i}\right)=\sum_{l} \sum_{j}\left[p_{l, t} \cdot q_{j, l, t}^{i}-C_{l, j}^{i}\left(q_{j, l, t}^{i}\right)\right]-\lambda_{t}(1-\tilde{\delta}) \sum_{l \in R E G} \sum_{j} q_{j, l, t}^{i} \cdot \tilde{e}_{j} .
$$

Note that (5) is essentially equivalent to equation (1), again assuming that emissions rates are constant over technologies and firms, except for the fact that the allowance price has now been scaled by $1-\tilde{\delta}$ for all firms. The Bohringer and Lange (2005) result implies that in a closed cap-and-trading system this results in the same outcomes that would be produced by a grandfathered allocation of allowances, except for the fact that allowance prices are increased by $1 /(1-\tilde{\delta})$. In this paper we examine the impact of this kind of updating in a much more complex production environment, with leakage, transmission, and capacity constraints. In addition, the actual updating policies proposed for the WCI do not reach the level of perfectly matching emissions rates, although some would come close. As the updating policy moves toward better correlation with emissions rates, we would expect these effects to become more pronounced. An empirical analysis such as this one is necessary to determine exactly how pronounced these impacts would be. 


\subsection{Transmission Network Management}

We assume that the transmission network is managed efficiently in a manner that produces results equivalent to those reached through centralized locational marginal pricing (LMP). For our purposes this means that the transmission network is utilized to efficiently arbitrage price differences across locations, subject to the limitations of the transmission network. Such arbitrage could be achieved through either bilateral transactions or a more centralized operation of the network. For now we simply assume that this arbitrage condition is achieved.

Mathematically, we adopt an approach utilized by Metzler,et al. (2003), to represent the arbitrage conditions as another set of constraints of the market equilibrium. Under the assumptions of a DC load-flow model, the transmission 'flow' induced by a marginal injection of power at location $l$ can be represented by a power transfer distribution factor $P T D F_{l k}$, which maps injections at locations, $l$, to flows over individual transmission paths $k$. Within this framework, the arbitrage condition will implicitly inject and consume power, $y_{l, t}$ to maximize available and feasible arbitrage profits as defined by

$$
\sum_{l \neq h}\left(p_{h, t}-p_{l, t}\right) y_{l, t}
$$

In the above arbitrage equation, the location $h$ is the arbitrarily assigned "hub" location from which all relative transmission flows are defined. Thus an injection of

power, $y_{l, t} \geq 0$, at location $l$ is assumed to be withdrawn at $h$. This arbitrage condition is subject to the flow limits on the transmission network, particularly the line capacities, $T_{k}$.

$$
-\bar{T}_{k} \leq P T D F_{l, k} \cdot y_{l, t} \leq \bar{T}_{k}
$$

This combination of arbitrage pressure and physical transmission constraints are resolved in the solution to the following langrangian.

$$
\max _{y_{l, t}} \sum_{l \neq h}\left[\left(p_{h, t}-p_{l, t}\right) y_{l, t}-\left(P T D F_{l, k} \cdot y_{l, t}-\bar{T}_{k}\right) \tau_{k, t}\right]
$$

Where $\tau_{k, t}$ is the shadow value of capacity on transmission path $k$ at time $t$. 


\subsection{Equilibrium Conditions}

Each firm has a limited capacity of each technology type in each location, which we denote by $\bar{q}_{j, l}^{i}$. Given the above framework, we can represent the resulting equilibrium as the set of quantities that simultaneously satisfy the following first order conditions. We represent as a complementarity condition, where the symbol $\perp$ signifies that vectors $x, y \geq 0$ and $x^{T} y=0$. For each firm $i$ and period $t$ :

$$
q_{j, l, t}^{i} \geq 0 \perp p_{t}-C_{l, j}^{i \prime}\left(q_{j, l, t}^{i}\right)-\lambda_{t} \cdot e_{j, l}^{i \prime}\left(q_{j, l, t}^{i}\right)-\gamma_{j, l, t}^{i} \leq 0 \quad \forall i, j, t, l \in R E G .
$$

and

$$
q_{j, l, t}^{i} \geq 0 \perp p_{t}-C_{l, j}^{i \prime}\left(q_{j, l, t}^{i}\right)-\gamma_{j, l, t}^{i} \leq 0 \quad \forall i, j, t, l \notin R E G .
$$

Here $\gamma_{j, l, t}^{i}$ is the shadow value of the capacity constraint on technology $q_{j, l, t}^{i}$.

$$
\gamma_{j, l, t}^{i} \geq 0 \perp \bar{q}_{j, l}^{i}-q_{j, t}^{i} \geq 0 \quad \forall i, j, t, l
$$

Each firm, taking prices as exogenous, sets its production so that marginal costs equal the price at the location of the production. This marginal cost component includes the costs of emissions allowances in locations subject to the emissions cap as well as the shadow price of the limited capacity of that technology.

Output-based Updating

As described above, output-based updating would allocate $\delta_{t}$ allowances per MWh to each firm. Differentiating the profit function (2) yields the following.

$$
q_{j, l, t}^{i} \geq 0 \perp p_{t}-C_{l, j}^{i \prime}\left(q_{j, l, t}^{i}\right)-\lambda_{t} \cdot\left(e_{j, l, t}^{i \prime}\left(q_{j, l, t}^{i}\right)-\delta_{t}\right)-\gamma_{j, l, t}^{i} \leq 0 \quad \forall i, j, t, l \in R E G .
$$

If the updating is instead fuel or technology specific, then the above condition is modified so that the allocation quantity, now $\delta_{j, t}$, can be unique to a technology type $j$.

$$
q_{j, l, t}^{i} \geq 0 \perp p_{t}-C_{l, j}^{i \prime}\left(q_{j, t}^{i}\right)-\lambda_{t} \cdot\left(e_{j, l, t}^{i \prime}\left(q_{j, l, t}^{i}\right)-\delta_{j, t}\right)-\gamma_{j, l, t}^{i} \leq 0 \quad \forall i, j, t, l \in R E G .
$$

\section{Environmental Constraint}


Along with equilibrium conditions (6) - (10), the equilibrium for a combined electricity and emissions market will include the following condition defining the allowance price for the overall compliance period.

$$
\lambda_{t} \geq 0 \perp \sum_{i} \sum_{j} \sum_{l \in R E G} q_{j, l, t}^{i} \cdot e_{j, l, t}^{i}\left(q_{j, l, t}^{i}\right)-e^{M A X} \leq 0 .
$$

Where, again, the symbol $\perp$ signifies complementarity between the constraint on available emissions allowances and the allowance price, which is the shadow price of that constraint. If there are excess emissions allowances, the price is zero; otherwise $\lambda_{t}$ is positive.

\section{Network Constraints}

Prices at individual locations will be determined by the production decisions of firms and the flows over the transmission network. The arbitrage minimization assumption described above produces the following condition.

$$
p_{h, t}-p_{l, t}-\sum_{k} P T D F_{l, k} \cdot \tau_{l, t}=0
$$

This reflects the general condition from an efficiently utilized network, that the prices between locations differ only by the additional costs of congestion of a shipment between those locations, as measured by the flows over lines times their shadow prices. There is a separate condition for potential congestion in each direction.

$$
\begin{aligned}
& \tau_{k, t}^{1} \geq 0 \perp P T D F_{l, k} \cdot y_{l, t}-\bar{T}_{k} \leq 0 \quad \forall k, t . \\
& \tau_{k, t}^{2} \geq 0 \perp \bar{T}_{k}-P T D F_{l, k} \cdot y_{l, t} \leq 0 \quad \forall k, t .
\end{aligned}
$$

When the inverse demand, marginal cost, and emissions functions are linear, as they are described below, the equilibrium conditions for each of the possible cap-and-trade regimes, along with the respective conditions for network operations and emissions market balance, combine to form a linear complementarity problem (Cottle, Pang, and Stone (1992)) with variables $q_{j, l, t}^{i}, y_{l, t}$ and dual values $\tau_{k, t}, \lambda_{t}$, and $\gamma_{j, l, t}^{i} \geq 0$. The solution to this complementarity problem constitutes a perfectly competitive equilibrium to this market, subject to the respective definitions of the cap region and allocation policy. Using the data sources and functional forms described in the following section, we calculate these equilibrium outcomes using the PATH solver algorithm (Dirske and Ferris, 1995) implemented through the AMPL math programming language. 


\section{Data Sources and Assumptions}

Our primary data source is the BASECASE dataset from Platts, which is in turn derived primarily from the continuous emissions monitoring system (CEMS) utilized by the U.S. Environmental Protection Agency (EPA) to monitor the emissions of large stationary sources. Almost all large fossil-fired electricity generation sources are included in this dataset. However, hydro-electric, renewable, and some small fossil generation sources are missing. The CEMS reports hourly data on several aspects of production and emissions. Hourly data on nuclear generation plants are included with fossil generation data in the BASECASE dataset. Here we utilize the hourly generation output and carbon emissions for available facilities.

These hourly output data are aggregated by firm and region to develop the "demand" in the simulation model. As described above, this is in fact a residual demand; the demand that is left after applying the output from non-CEMS plants. Plant cost, capacity, and availability characteristics and regional fuel prices are then taken from the Platts POWERDAT dataset. These data are in turn derived from mandatory industry reporting to the Energy Information Administration (EIA) and the National Electric Reliability Council (NERC).

These data are then combined to create a demand profile and supply functions for periods in the simulation. Although hourly data are available, for computational reasons we aggregate these data into representative time periods. There are 20 such periods for each of the four seasons, yielding 80 explicitly modeled time periods. As California policy was the original focus of this work, the aggregation of hourly data was based upon a sorting of the California residual demand. California aggregate production was sorted into 20 bins based upon equal MW spreads between the minimum and maximum production levels observed in the 2007 sample year. A time period in the simulation therefore is based upon the mean of the relevant market data for all actual 2007 data that fall within the bounds of each bin. For example, every actual hour (there were 54) during Spring 2007 in which California residual demand fell between 6949 and 7446 MW were combined into a single representative hour for simulation purposes. The resulting emissions from this hour were then multiplied by 54 to generate an annualized equivalent total level of emissions.

The number of season-hour observations in each bin is therefore unbalanced, there are relatively few observations in the highest and lowest production levels, and more closer to the median levels. The demand levels used in the simulation are then based upon the mean production levels observed in each bin. In order to calculate aggregate emissions, the resulting outputs for each simulated demand level was multiplied by the number of actual market hours used to produce the input for that simulated demand level. 
Table 1: Demand by Region and Season

\begin{tabular}{lrrrr}
\hline \hline Season & AZNM & CA & NWPP & non-WCI \\
\hline Winter & 10925 & 11641 & 10781 & 16407 \\
Spring & 12130 & 11369 & 8394 & 15604 \\
Summer & 14705 & 16314 & 12823 & 18766 \\
Fall & 10943 & 13504 & 12878 & 16622 \\
\hline
\end{tabular}

In the following sub-sections, we describe further the assumptions and functional forms utilized in the simulation.

\subsection{Market Demand}

End-use consumption in each location is represented by the demand function $Q_{l, t}=$ $\alpha_{l, t}-\beta_{l} p_{l, t}$, yielding an inverse demand curve defined as

$$
p_{l t}=\frac{\alpha_{l, t}-\sum_{i, j} q_{i, j, t}-y_{i, t}}{\beta_{l}}
$$

where $y_{i, t}$ is the aggregate net transmission flow into location $l$. The intercept of the demand function is based upon the actual production levels in each location calculated as described above. The mean hourly demand is summarized by GHG regulatory region in Table $1 .{ }^{16}$ In each representative hour, demand is assumed to be at the levels reflected in Table 1 when market prices are equal to the levels observed in the actual market hours from which the demand numbers are taken. In other words, we model a linear demand curve that passes through the observed price-quantity pairs for each period. As electricity is an extremely inelastic product, we utilize an extremely low value for the slopes of this demand curve. For each region, the regional slope of the demand curve is set so that the median elasticity in each region is $-.05 .{ }^{17}$

\footnotetext{
${ }^{16}$ As described below, supply and demand regions can be characterized as belonging in one of 5 electrical zones or one of the four zones distinguished by climate regulation listed in Table 1 .

${ }^{17}$ When the market is modeled as perfectly competitive, as it is here, the results are relatively insensitive to the elasticity assumption, as price is set at the marginal cost of system production and the range of prices is relatively modest.
} 


\subsection{Fossil-Fired Generation Costs and Emissions}

We explicitly model the major fossil-fired thermal units in each electric system. Because of the legacy of cost-of-service regulation, relatively reliable data on the production costs of thermal generation units are available. The cost of fuel comprises the major component of the marginal cost of thermal generation. The marginal cost of a modeled generation unit is estimated to be the sum of its direct fuel, $\mathrm{CO} 2$, and variable operation and maintenance (VO\&M) costs. Fuel costs can be calculated by multiplying the price of fuel, which varies by region, by a unit's 'heat rate,' a measure of its fuel-efficiency.

The capacity of a generating unit is reduced to reflect the probability of a forced outage of each unit. The available capacity of generation unit $i$, is taken to be $\left(1-f o f_{i}\right) * c a p_{i}$, where $\mathrm{cap}_{i}$ is the summer rated capacity of the unit and $f_{o} f_{i}$ is the forced outage factor reflecting the probability of the unit being completely down at any given time. ${ }^{18}$ Unit forced outage factors are taken from the generator availability data system (GADS) data that is collected by the North American Reliability Councils. These data aggregate generator outage performance by technology, age, and region.

Generation marginal costs are derived from the costs of fuel and variable operating and maintenance costs for each unit in our sample. Platts provides a unit average heatrate for each of these units. These heat-rates are multiplied by a regional average fuel cost for each fuel and region, also taken from Platts. Costs for each technology type are then aggregated by firm and region, and then represented with a single quadratic function for each of five technology types, further separated by firm and region. Marginal cost of technology $j$ at location $l$ for firm $i$ is therefore an affine function.

$$
C_{l, j}^{i \prime}\left(q_{j, l, t}^{i}\right)=k_{l, j}^{i}+c_{l, j}^{i} q_{l, j, t}^{i}
$$

These cost functions are derived by aggregating the generation of each firm by region and technology type. The five technology categories are coal, gas combined cycle (CCGT), conventional (steam) gas, gas combustion turbine (CT), and oil.

There are ten firms consisting of the nine largest fossil generation producers and a "fringe" firm derived from the aggregation of the generation from all remaining firms. The generation capacity of each of these firms is summarized by technology type in Table 2 .

Emissions Rates

\footnotetext{
${ }^{18}$ This approach to modeling unit availability is similar to Wolfram (1999) and Bushnell, Mansur and Saravia (2008).
} 
Table 2: Generation by Ownership and Fuel Type

\begin{tabular}{lrrrrr}
\hline \hline Firm & Coal & CCGT & Gas St & Gas CT & Oil \\
\hline BRKA & 6104 & 629 & 235 & 319 & 0 \\
CPN & 0 & 4802 & 0 & 915 & 0 \\
DYN & 0 & 2120 & 2875 & 0 & 0 \\
EIX & 720 & 1373 & 0 & 237 & 0 \\
LADWP & 2117 & 1303 & 1929 & 282 & 0 \\
PW & 1741 & 1569 & 430 & 486 & 0 \\
SALTRP & 1802 & 1537 & 407 & 0 & 0 \\
SEMPRA & 0 & 2366 & 0 & 46 & 0 \\
XCEL & 2593 & 690 & 107 & 0 & 0 \\
Others & 14153 & 16338 & 12049 & 4840 & 629 \\
\hline
\end{tabular}

Emissions rates are based upon the fuel-efficiency (heat-rate) of a plant and the carbon intensity of the fuel burned by that plant. They are modeled as affine functions, with rates differentiated by firm, location, and technology. This yields a functional form of

$$
e_{l, j}^{i \prime}\left(q_{l, j, t}^{i}\right)=E_{l, j}^{i}+\epsilon_{l, j}^{i} q_{l, j, t}^{i} .
$$

\subsection{Transmission Network}

Our regional markets are highly aggregated geographically. The region we model is the electricity market contained within the U.S. portion of the Western Electricity Coordinating Council (WECC). The WECC is the organization responsible for coordinating the planning investment, and general operating procedures of electricity networks in most states west of the Missisipi. The multiple sub-networks, or control areas, contained within this region are aggregated into the four "sub-regions." Between (and within) these regions are over 50 major transmission interfaces, or paths. Due to both computational and data considerations, we have aggregated this network into a simplified, 5 region network consisting primarily of the 4 major subregions. ${ }^{19}$ Figure 1 illustrates the areas covered by these regions. The states in white, plus California, constitute the US participants in the WCI.

\footnotetext{
${ }^{19}$ The final "node" in the network consists of the Intermountain power plant in Utah. This plant is connected to southern California by a high-capacity DC line, and is often considered to electrically be part of California. Because under some regulatory scenarios, it would not in fact be part of California for GHG purposes, it is represented as a separate location that connects directly to California.
} 
Given aggregated level of the network, we model the relative impedance of each set of major pathways as roughly inverse to their voltage levels. The network connecting AZNM and the NWPP to CA is higher voltage $(500 \mathrm{KV})$ than the predominantly 345 $\mathrm{KV}$ network connecting the other regions. For our purposes, we assume that these lower voltage paths yield $5 / 3$ the impedance of the direct paths to CA.

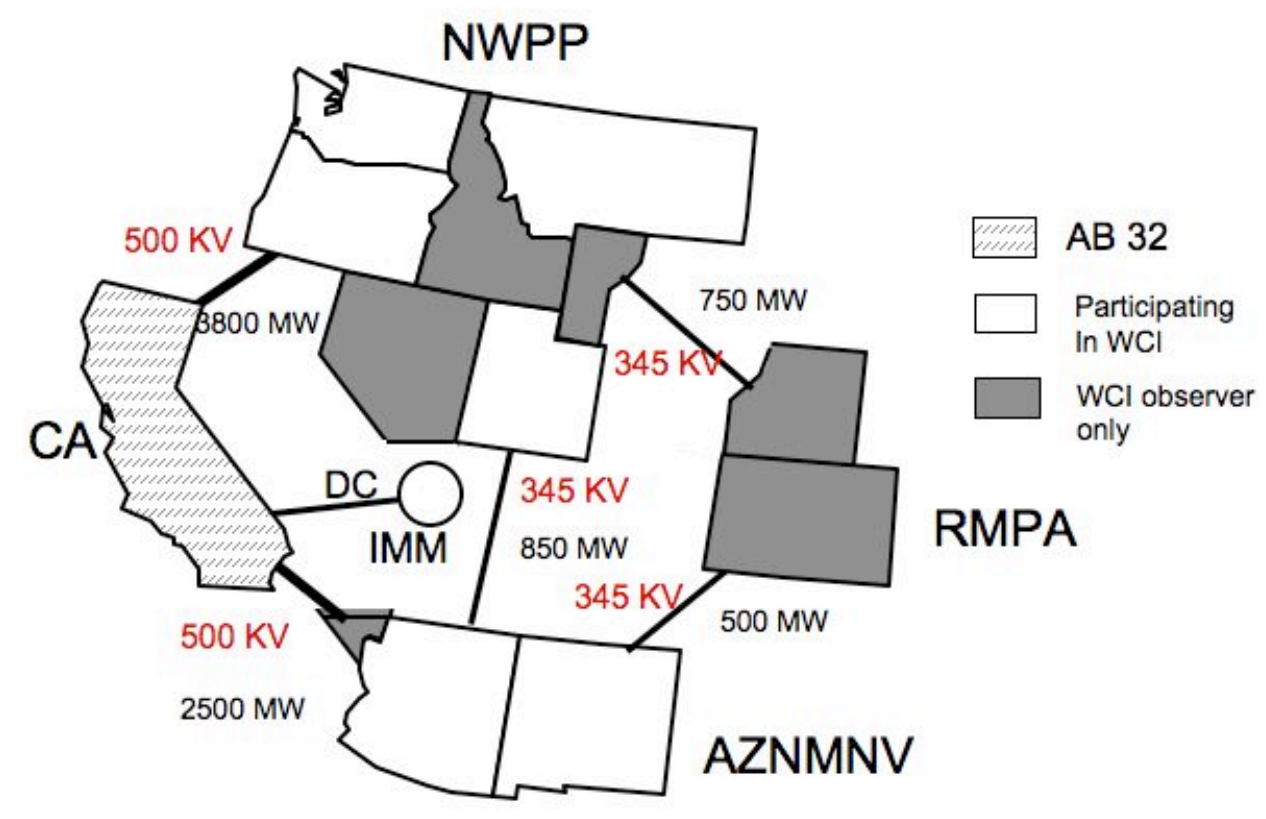

Figure 1: Western Regional Network and Cap-and-Trade Regions

There are sub-regions with both the NWPP and AZNM areas that would also not be subject to the currently organized WCI agreement. These include the states of Nevada and Idaho, as well as power plants located on tribal lands in the desert southwest. In each case these regions were considered to electrically be part of the region in which they were located, but for purposes of GHG regulation were treated as separate regions.

The flow capacity over the regional interfaces are ideally based upon the amount of "slack" capacity remaining over these interfaces under actual market conditions. We have obtained data from the WECC for hourly flows and total available capacity for each hour 
Table 3: Available Slack Transmission Capacity by Region and Period (MW)

\begin{tabular}{llrrrrr}
\hline \hline Season & Period & NW-CA & SW-CA & RM-NW & RM-SW & SW-NW \\
\hline \multirow{2}{*}{ Spring } & Off-peak & 5649 & 3023 & 731 & 523 & 709 \\
& Peak & 3692 & 2855 & 837 & 505 & 772 \\
\multirow{2}{*}{ Summer } & Off-peak & 2886 & 3320 & 935 & 490 & 762 \\
& Peak & 1634 & 3337 & 957 & 451 & 922 \\
\multirow{2}{*}{ Fall } & Off-peak & 5012 & 2604 & 540 & 369 & 402 \\
& Peak & 3101 & 2757 & 652 & 318 & 666 \\
& Off-peak & 5473 & 2362 & 458 & 278 & 319 \\
\multirow{2}{*}{ Winter } & Peak & 3683 & 1921 & 545 & 231 & 396 \\
\hline
\end{tabular}

of the first 10 months of 2007. Unfortunately data for November and December 2007 were not yet available.

We characterize the available additional capacity over the key paths according to the average difference between available capacity (or ATC) and actual flows over each key transmission path. These differences are averaged over peak and off-peak periods for each of the four seasons represented in our model, where the winter season is based on the average of October only. ${ }^{20}$ The resulting available remaining import capacity over each transmission interface is summarized in Table 3.

\section{Results}

Following the assumptions described above, we simulate the electricity production for the western electricity market under a variety of assumptions about the scope and design of cap-and-trade for CO2. For the geographic scope of the regulation, we first simulate operations under no-cap at all to establish a reference level for the other simulation results. Then we examine CO2 caps applied to California-only, to all (US) states participating in the WCI, and finally to all states (and tribal areas) in the western market. For each

\footnotetext{
${ }^{20}$ In implementing our model, "off-peak" hours are defined as falling in the lowest 6 out of 20 of demand 'bins' that are described above. All other hours are treated as "on-peak".
} 
of these cap-and-trade scenarios, we assume that the cap is set at $85 \%$ of the CO2 emissions from the "no-cap" scenario. For all of the results in this section, we assume that allowances are allocated exogenously and therefore do not effect the output decisions of firms. As described above, the simulation encompasses 8760 hours of actual market data that were aggregated into 80 representative hours, 20 for each season. These representative hourly results were then multiplied by the number of actual hours in each of the "bins" from which these hours were based upon. The results reported below are therefore annual totals, based upon 8760 hours of production.

Table 4 summarizes the aggregate annual CO2 emissions for each of the key regulatory regions. Results are reported for each of the simulated scenarios, as well as the actual (2007) aggregate emissions, as measured by CEMS, for each of these regions. First note that simulated emissions under the "no cap" scenario are about $6 \%$ lower than measured actual emissions. This difference is most pronounced in the California region. As illustrated in Figure 2, these differences are driven by the relative production of combined cycle (CCGT) to less efficient (CT and ST) gas plants. Production from less efficient plants is lower, and from CCGT plants higher, in our simulation than in actuality. This is most likely due to several factors. First, by aggregating actual hourly observations into representative market hours, we in effect truncate the peak demand levels of the system into a single level representing the average of a set of high demand hours. The operation of these less efficient plants is usually concentrated in these very high demand hours. Second, our simulation ignores inter-temporal operating constraints on plants, and CCGT plants are in fact less nimble than our simulation implicitly assumes them to be. Third, while we model major inter-regional transmission constraints, other more local constraints could force the operation of less efficient generation.

Setting aside these differences for the moment, we turn our focus to the impacts of capand-trade regulations relative to our simulated no-cap case. As would be expected, a cap applied only to California, as originally envisioned under AB 32, would result in significant leakage. Although California emissions decline by $5.5 \mathrm{~mm}$ Tons as required by the cap, aggregate west-wide emissions decline by less than one mmTon. Emissions prices are correspondingly low, at only $10.80 \$ /$ ton, due to the fact that compliance through leakage is a relatively inexpensive option. When the cap is applied to the currently configured WCI, leakage is greatly reduced, but still roughly $1 / 3$ of the $26 \mathrm{mmTon}$ reduction in WCI state emissions is picked up in the nearly $7 \mathrm{~mm}$ Ton increase in non-WCI emissions. When the cap is applied to the entire market, allowance prices rise to just below $\$ 44$ /ton. This can be interpreted as the value required to reach a true reduction of 26 mmTons over the entire region without any leakage, as opposed to a reduction of 26 mmTons under the cap that is offset by an increase outside the cap. One implication of this comprehensive carbon cap is that California emissions increase. This is because the generation capacity inside California's borders is relatively clean, and a west-wide 


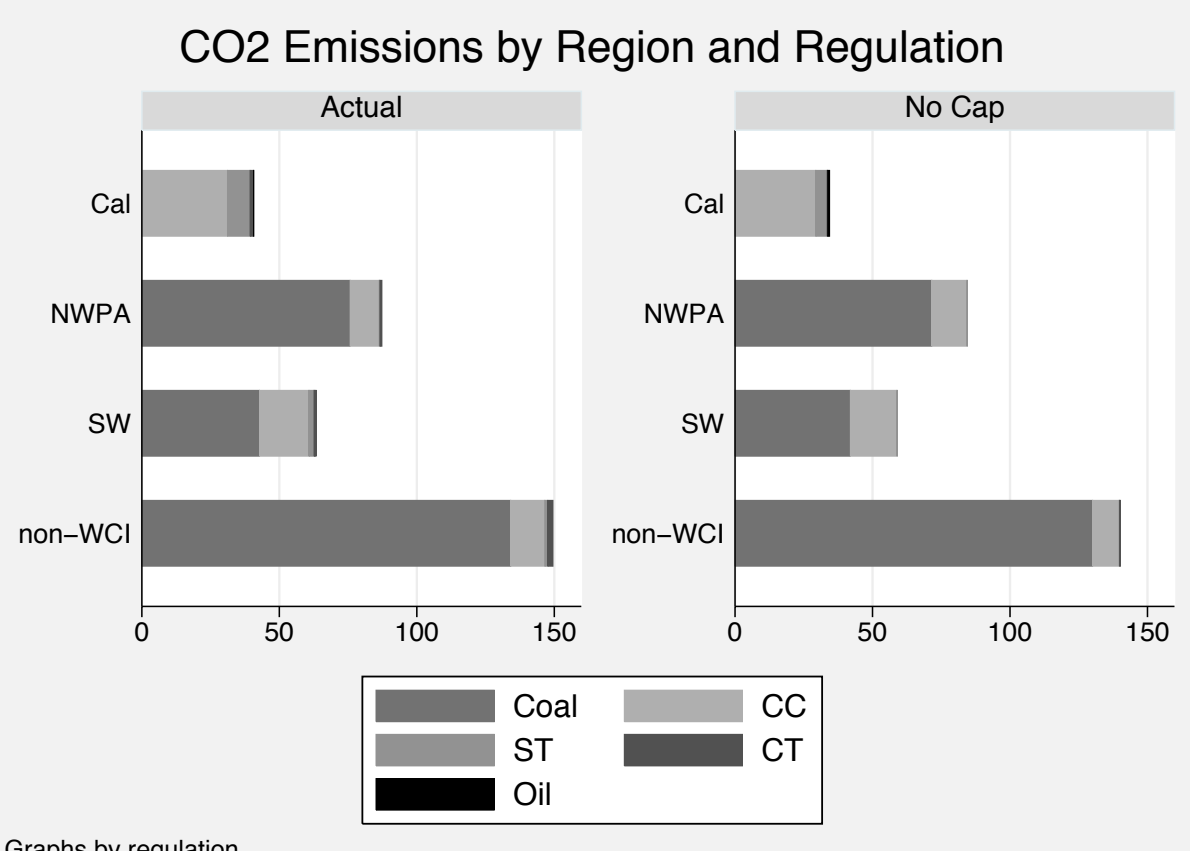

Graphs by regulation

Figure 2: Actual vs. Baseline Emissions 
Table 4: Scope of Regulation: Emissions by Region (mmTons)

\begin{tabular}{lrrrrrr}
\hline \hline & & & & & & Carbon \\
Regulation & CA & NWPP & SW & non-WCI & Total & Price \\
\hline Actual (CEMS) & 40.71 & 87.30 & 63.37 & 149.52 & 340.9 & NA \\
No cap & 35.99 & 83.75 & 58.00 & 139.46 & 317.2 & NA \\
Cal only & 30.55 & 84.78 & 60.04 & 141.25 & 316.62 & 10.80 \\
WCI cap & 32.33 & 71.76 & 46.88 & 147.95 & 298.92 & 40.30 \\
WECC cap & 36.87 & 74.32 & 48.99 & 131.08 & 291.26 & 43.80 \\
\hline
\end{tabular}

Table 5: Change from Actual Exports by Region (Average MWh)

\begin{tabular}{lrrrr}
\hline \hline Regulation & CA & NWPP & SW & non-WCI \\
\hline No cap & 347 & 509 & -97 & -759 \\
Cal only & -969 & 802 & 468 & -301 \\
WCI cap & -156 & -469 & -846 & 1472 \\
WECC cap & 1012 & 79 & -204 & -888 \\
\hline
\end{tabular}

reduction in overall emissions is most easily accomplished by reducing output from coal generation in other states, and replacing it with gas output from California.

Table 5 summarizes the net injections into the west-wide network originating from each region. Recall that the "demand" modeled here is based upon actual production, rather than end-use demand, so it is the change in these figures, summarized below, that is relevant, rather than their absolute levels. In the table above, a negative figure implies a net import from the region relative to the actual period, while a positive number implies a net export. For example, California imported 347 MW per hour less under our base-case simulation than was implied by the actual data for the same periods, resulting in a net increase of $347 \mathrm{MW}$ of CA production. Consistent with the emissions results, one can see the sizable swing in imports into California (around $1200 \mathrm{MW} / \mathrm{h}$ ) under a California-only cap, as well as the large increase in net injections from the non-WCI region (about $2200 \mathrm{MW} / \mathrm{h}$ ) under the WCI cap. Note again that flows into California experience a substantial decrease under the comprehensive west-wide cap.

The impact of these regulations on wholesale electricity prices in the various regions is summarized in table 6 . Note that the regional breakdown in these columns is slightly different than in the previous tables. These are electricity market areas, rather than 
Table 6: Scope of Regulation: Electricity Prices by Region (Average \$/MWh)

\begin{tabular}{lrrrr}
\hline \hline Regulation & Cal & NWPP & AZNMNV & RMPA \\
\hline No cap & 57.14 & 59.12 & 60.44 & 64.89 \\
Cal only & 59.45 & 62.19 & 64.00 & 66.56 \\
WCI cap & 75.75 & 77.04 & 77.90 & 75.66 \\
WECC cap & 78.8 & 81.68 & 83.61 & 89.03 \\
\hline
\end{tabular}

CO2 regulatory areas. The NWPP includes both capped and uncapped states, while the RMPA has no WCI states in its region. Prices rise substantially under the more comprehensive $\mathrm{CO} 2$ caps, even in regions not covered by the cap. This is due to the increased exports from these regions.

\subsection{Impacts of Allocation Policies}

We now turn to the question of how the various policies for allocation of allowances impacts prices and operations. Table 7 summarizes the emissions by regulatory region for the various permutations of a policy applied to the WCI, including the baseline "nocap" case. In all cases, except the no-cap case, an identical emissions cap of roughly 150 mmTons, or $85 \%$ of the uncapped level, is applied to the WCI region. The row labeled "WCI cap" applies to any allocation policy, such as auctioning or grandfathering, where allocations are exogenous to ongoing market outcomes. There were also two versions of allocations through updating that we considered. The row "WCI updating" refers to output-based updating. Under this policy, we assumed that $80 \%$, or $120 \mathrm{mmTons,} \mathrm{of} \mathrm{the}$ allowances are allocated under the updating policies, with the remainder either allocated in some exogenous fashion or auctioned off. Similarly, in the "Fuel-based" updating scenario, we also assume that $80 \%$ of the allowances were allocated, and the remainder auctioned. Under the Fuel-based updating scenario, we follow the CPUC's (CPUC, 2008) proposed allocation ratios. This proposal would allocate twice as much to coal generation as it would to gas generation. These ratios apply only to the fraction of total allowances allocated, so that the net allocation received by a coal plant was equivalent to 0.75 tons/MWh, while the allocation to gas plants would be 0.375 tons/MWh. ${ }^{21}$ We established these allocation levels so that the total number of allowances assigned under both the fuel-based and output-based allocation proposals was the same. This is truly "fuel-based" updating, with the distinction between updating being based upon

\footnotetext{
${ }^{21}$ There are very few oil plants in the sample, and they received allocations in equal ratios as those of gas plants.
} 
fuel, rather than technology or explicit emissions rates. We therefore would not expect as extreme an impact from this allocation as that implied by equation (5). However, differentiation by fuel does capture a significant portion of the emissions rate differences between plants, so some significant differences from output-based updating would be expected.

As seen from Tables 7 and 8 the impacts of the allocation policies are indeed significant. Carbon emissions in uncapped "non-WCI" regions increase by roughly $7 \mathrm{mmTons}$ (or $1 / 3$ of the required reduction), under a WCI cap with no updating. When outputbased updating is applied to firms within the WCI, this leakage of emissions is reduced to roughly 2 mmTons (or less than 1/10 of the required reductions). Also note that emissions within California rise substantially with the application of output-based updating. As can be seen from Figure 3, this is due to a large decrease in coal production. This is because output-based allocation favors gas generation relative to coal-generation, and California has no coal-based utility scale generation. The output-based updating therefore had a non-trivial impact on mitigation of leakage from the WCI region. When the updating approach is changed instead to be fuel-based, however, this mitigation of leakage is largely offset. Total emissions are only $2 \mathrm{mmTons}$ lower than when no updating at all is applied.

The most striking impact of the updating policies is on the prices of the emissions allowances. Allowance prices rise from about $\$ 40 /$ ton without updating to $\$ 45.60 /$ ton with output-based updating. As predicted, the fuel-based updating approach has a substantial impact on allowance prices, raising them to just under $\$ 67.50 /$ ton. Recall that this model reflects only the electricity sector, and therefore the distortions from these price impacts are contained within this industry and are largely offset by the updating policies that caused them. When one considers that this market will eventually include most major sources of $\mathrm{CO} 2$ emissions within the west, and be linked with other regions through trades with other $\mathrm{CO} 2$ markets, as well as offset programs, the potential distortions caused by such an inflationary impact on allowance prices become a significant concern.

The results summarized in Table 8 tell a similar story, this time in terms of energy exports rather than emissions. The application of a CO2 cap on the WCI states results in a net increase of $2200 \mathrm{MW}$ per hour in net exports from the non-WCI regions, which swing from net importers to net-exporters of power. When output based updating is applied, the WCI region again becomes a net importer. As with emissions, the application of fuel-based updating reverses the effects of output-based updating, raising net-exports from the non-WCI regions by an average of about $700 \mathrm{MWh}$.

Table 9 summarizes the price impacts of the cap, and of the updating policies. The imposition of the cap (again requiring a 15\% reduction from the status quo) raises Cal- 


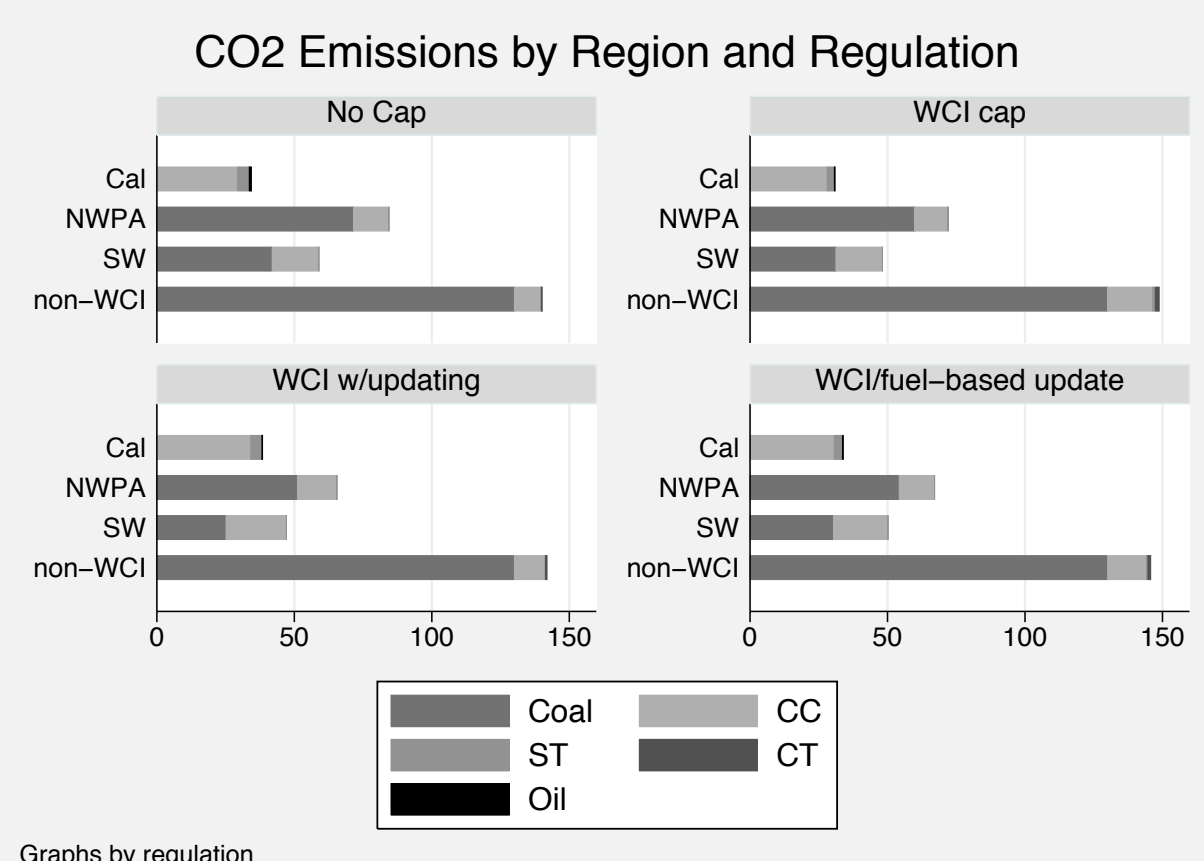

Graphs by regulation

Figure 3: Impact of Updating Policies 
Table 7: Effect of Updating: Emissions by Region (mmTons)

\begin{tabular}{lrrrrrr}
\hline \hline & & & & & & Carbon \\
Regulation & CA & NWPP & SW & non-WCI & Total & Price \\
\hline No cap & 34.4 & 84.4 & 59.0 & 140.2 & 318.0 & NA \\
WCI cap & 30.9 & 72.0 & 48.2 & 148.8 & 299.9 & 40.30 \\
WCI updating & 38.4 & 65.5 & 47.2 & 141.9 & 293.0 & 45.60 \\
Fuel-based & 33.8 & 67.1 & 50.2 & 145.7 & 296.8 & 67.50 \\
\hline
\end{tabular}

Table 8: Change from Actual Exports by Region (Average MWh)

\begin{tabular}{lrrrr}
\hline \hline Regulation & CA & NWPP & SW & non-WCI \\
\hline No cap & 347 & 509 & -97 & -759 \\
WCI cap & -156 & -469 & -846 & 1472 \\
WCI updating & 1169 & -799 & -581 & 210 \\
Fuel-based & 357 & -684 & -585 & 913 \\
\hline
\end{tabular}

ifornia wholesale average prices from around $\$ 58 / \mathrm{MWh}$ to around $\$ 75 / \mathrm{MWh}$. The almost $\$ 20 / \mathrm{MWh}$ increase is consistent with the facts that CO2 costs are about $\$ 40$ /ton in this scenario, and that gas plants, which emit roughly $1 / 2$ ton per-MWh are almost always the marginal, price-setting technology. When output-based updating is applied, most of this impact on the market-clearing price is eliminated, as prices "fall" from 75 to about $\$ 62 / \mathrm{MWh}$. Yet again the fuel-based updating policy reverses the impacts of the output-based updating. Prices under fuel-based updating average around $\$ 70 /$ MWh.

Profit Impacts of Allocation Policies

Table 9: Effect of Updating: Electricity Prices by Region (Average $\$ / \mathrm{MWh}$ )

\begin{tabular}{lrrrr}
\hline \hline Regulation & Cal & NWPP & AZNMNV & RMPA \\
\hline No cap & 57.14 & 59.12 & 60.44 & 64.89 \\
WCI cap & 75.75 & 77.04 & 77.9 & 75.66 \\
WCI updating & 62.75 & 65.01 & 66.53 & 68.52 \\
Fuel-based & 69.32 & 71.5 & 72.95 & 72.13 \\
\hline
\end{tabular}


We now examine how the allocation policies impact the emissions costs and operating profits of firms. Recall that the the updating schemes are largely motivated by a desire to offset the cost impacts to high emitting firms and limit any perceived windfalls to low emissions firms. Table 10 summarizes the net costs of emissions regulations on firms. The net emissions costs is defined here as the costs of emissions allowances required by the firm under the cap-and-trade regulation less the value of the emissions allowances allocated under the various allocation approaches. As before the fuel-based and outputbased contingent allocation schemes assume that $80 \%$ of total allowances (about 120 mmTons) are allocated to producers. The last column in this table considers an exogenous grandfathered allocation of the same quantity, based upon the emissions under the "nocap" scenario, which here serves as the proxy for historic emissions.

Note that when a firm receives more in allocation than it must surrender due to its actual emissions, the net costs can be negative. This is in fact the case for largely gas-based producers, such as Calpine (CPN) and Dynegy (DYN) under the outputbased allocation approach. In contrast, coal-heavy producers such as PacifCorp (owned by BRKA) and Arizona Public Service (owned by PW) have significant emissions costs under any scenario. Despite the skewing of allowance allocation in favor of coal producers under the fuel-based allocation approach, net emissions costs are only slightly lower for these firms under this approach. The reason is that the higher equilibrium allowance prices largely offset the increased allocation quantities these firms receive under the fuelbased approach. These firms are clearly better off under grandfathering, which also skews allocations their way without impacting allowance prices.

The picture becomes more complex when one considers the net effects of the allocation scheme on product (electricity) prices as well as emissions costs. Table 11 summarizes the operating profits of the firms under the assumption that each firm were selling all its output at market-clearing prices, rather than at a a regulated cost-based rate. It is important to recognize that several of the firms in this table are in fact either regulated or government-owned. ${ }^{22}$ Therefore these results are more a qualitative representation of the general net revenue and cost effects than a literal assessment of each firms bottom line impact. The profits are therefore defined as the total revenues (assuming market-based sales) less the net emissions costs from table 10 as well as the total production costs (fuel and operating expenses).

The results in table 11 highlight the complex interaction between the allocation policy, allowance prices, and electricity prices. Recall that, based on allocation and emissions costs alone, gas-intensive firms appeared to benefit from output-based allocation. However, output-based allocation also greatly limited the pass-through of carbon costs to

\footnotetext{
${ }^{22}$ The results also reflect only revenue of sales from thermal generation sources. Firms with substantial nuclear and hydro generation would benefit disproportionately more from a higher allowance price.
} 
Table 10: Net Emissions Costs by Firm (Millions \$)

\begin{tabular}{lrrrr}
\hline \hline Firm & $\begin{array}{r}\text { No } \\
\text { Allocation }\end{array}$ & $\begin{array}{r}\text { Fuel- } \\
\text { based }\end{array}$ & $\begin{array}{r}\text { Output- } \\
\text { based }\end{array}$ & $\begin{array}{r}\text { Grand- } \\
\text { fathering }\end{array}$ \\
\hline BRKA & 894.2 & 439.5 & 489.6 & 292.2 \\
CPN & 394.9 & 41.9 & -96.7 & 126.4 \\
DYN & 261.6 & 6.3 & -77.2 & 101.1 \\
EIX & 157.6 & 6.3 & -44.1 & 44.3 \\
LADWP & 660.8 & 262.1 & 280.3 & 227.1 \\
PW & 286.4 & 120.5 & 100.4 & 97.8 \\
SALTRP & 341.8 & 135.8 & 123.3 & 110.7 \\
SEMPRA & 203.4 & -0.5 & -67.7 & 58.4 \\
XCEL & 0.0 & 0.0 & 0.0 & 0.0 \\
Others & 2883.3 & 1107.3 & 743.9 & 1261.0 \\
\hline
\end{tabular}

electricity prices. This results in reduced revenues for all firms. While gas intensive firms such as CPN still prefer contingent allocation to auctioning, they actually do better under fuel-based allocation than output-based. This is despite the fact that fuel-based allocation was intended to limit their perceived windfall benefits from allocation. However, since electricity prices are higher under fuel-based, the increased revenue from this scenario more than offsets the reduced allocation in allowances relative to output-based updating for these firms.

For high carbon firms, such as the coal-heavy BRKA and PW, the contingent allocation approaches look even worse. The combination of higher emissions costs due to the inflated allowance prices and lower electricity revenues reduce profits under these allocation schemes to below those seen with no allocation at all. While fuel-based is in fact preferred to output-based allocation by such firms, neither is particularly appealing. As before, grandfathering is the clear winner from the perspective of such firms.

\section{Conclusions}

While the establishment of cap-and-trade regulation, as opposed to command-and-control regulations, is largely motivated by a desire to provide incentives for the efficient mitigation of pollution, many other policy goals are often at play. These goals include mitigating the cost impacts of climate regulation on both consumers and on the firms to which the regulation will be applied. As climate policy advances in the United States, 
Table 11: Wholesale Market Net Revenues from Fossil Generation (Millions \$)

\begin{tabular}{lrrrrr}
\hline \hline Firm & No & $\begin{array}{r}\text { Fuel- } \\
\text { Allocation }\end{array}$ & $\begin{array}{r}\text { Output- } \\
\text { based }\end{array}$ & No Cap & $\begin{array}{r}\text { Grand- } \\
\text { fathering }\end{array}$ \\
\hline BRKA & 1746 & 1988 & 1636 & 1587 & 2397 \\
CPN & 389 & 605 & 578 & 190 & 670 \\
DYN & 225 & 376 & 355 & 80 & 401 \\
EIX & 401 & 453 & 413 & 245 & 508 \\
LADWP & 442 & 711 & 535 & 438 & 899 \\
PW & 517 & 578 & 470 & 377 & 720 \\
SALTRP & 513 & 608 & 496 & 409 & 747 \\
SEMPRA & 244 & 338 & 302 & 91 & 385 \\
XCEL & 1140 & 1041 & 953 & 863 & 1140 \\
XFRINGE & 4262 & 4962 & 4168 & 3489 & 6858 \\
\hline
\end{tabular}

these ancillary goals are playing a prominent role in the design of emissions markets. The allocation of emissions allowances is seen as a critical tool for achieving these policy goals.

We have studied these issues in the context of the proposed California and Western Climate Initiative cap and trade programs, by focusing on the electricity market that spans these regions. In this context, the mitigation of regulatory circumvention through leakage is an additional concern. Indeed, we find that even with the expansion of the western cap to 7 states, leakage could still be significant. Here the proposals for the contingent allocation of allowances, either linked to the output or the fuel input of a plant, can have a significant impact. Output-based allocation largely achieves the stated goals of policy-makers by effectively mitigating leakage and also electricity prices. However, when the allocation is linked to the fuel of the resource, rather than strictly to its output, most market outcomes closely resemble those seen under an exogenous allocation scheme such as auctioning or grandfathering. Allowance prices, however, rise considerably to levels more than double that seen under an exogenous allocation. Although the primary goals of input-based allocation are to insulate high-carbon firms from cost shocks and prevent "windfalls" to low-carbon producers, these goals are largely unachieved even when $80 \%$ of the allowances are allocated.

While we believe these results have important practical implications for the design of the western electricity market, we need to note many caveats that limit the interpretation of these results as a forecast of WCI cap-and-trade market results. First, we limit our analysis to the electricity industry, which will dominate the WCI market for its first 
phase, but will then be combined with several other sectors, including transportation fuels. Second, we model only traditional "source-based" market implementations, where the WCI is pursuing a hybrid design that will combine the source-based regulation of plants located within the WCI with attempts to account for the carbon content of imports into that region.

It is important to examine the specific implications of this "first-deliverer" approach, which will almost certainly limit leakage below the levels we find here. However, we believe that the source based model studied here provides an accurate picture of the implications of allocation policies under either a first-deliverer or source-based design. There are also some factors that may limit the leakage-mitigating impact of the firstdeliverer approach. Although regulators can attempt to apply carbon levels to imports, these attempts can be bypassed by a reshuffling of transactions. It is suspected that, under such a system, relatively clean production will be identified as the 'source' of imports into the WCI. Second, and more importantly, the WCI is often a net exporter of power. The first-deliverer design cannot deal with leakage when it is driven by end-use demand located outside the regulators jurisdiction.

When one considers the implications of an integration of the electricity sector with other sectors, the aspect of fuel-based updating that is most problematic is the greatly increased allowance price. The concern is that the upward price pressure from the sector receiving updates will lead the mitigation to be concentrated in other sectors that do not. In those sectors, marginal emissions costs will in fact be much higher than in the sectors receiving updated allocations. For example, one would expect the utilization of unconventional "offsets," such allowances for retrofitting inefficient facilities, to greatly increase as the result of the inflationary pressure on allowance prices caused by updating.

More generally, as discussions concerning national cap-and-trade regime for CO2 continue, these results, consistent with previous work, highlight the potential distortions that updating can introduce into a cap-and-trade market. Just as important from the point of view of policy-makers, careful attention must be paid to the equilibrium effects of any allocation proposal. These effects can be significant if the share of allowances awarded through updating comprise a substantial share of total allowances. In particular, the more allocation rates are tailored to specific industries, the more the scheme takes on characteristics of emissions-based updating. This holds the risk of greatly diluting the beneficial effects of output-based allocation. 


\section{References}

[1] M. Ahman, D. Burtraw, J. Kruger, and L. Zetterberg. A ten-year rule to guide the allocation of eu emission allowances. Energy Policy, 35(3):17181730, 2006.

[2] M. Ahman and K. Holmgren. New entrant allocation in the nordic energy sectors: Incentives and options in the eu ets. Climate Policy, 6:423-440, 2006.

[3] C. Bohringer and A. Lange. Economic implications of alternative allocation schemes for emission allowances. The Scandinavian Journal of Economics, 107(3):563-581, 2005.

[4] C. Bohringer and A. Lange. On the design of optimal grandfathering schemes for emissions allowances. European Economic Review, 49:2041-2055, 2005.

[5] D. Burtraw. Regulating co2 in electricity markets: Sources or consumers? Climate Policy, 8:588-606, 2008.

[6] D. Burtraw, K. Palmer, and D. Kahn. Allocation of co2 emissions allowances in the regional greenhouse gas cap-and-trade program. Discussion Papers dp-05-25, Resources For the Future, June 2005.

[7] J. Bushnell, E.T. Mansur, and C. Saravia. Vertical Arrangements, Market Structure, and Competition: An Analysis of Restructured US Electricity Markets. American Economic Review, 98:237-66, 2008.

[8] J. Bushnell, C. Peterman, and C. Wolfram. Local Solutions to Global Problems: Climate Change Policies and Regulatory Jurisdiction. Review of Environmental Economics and Policy, 2008.

[9] California Public Utility Commission. Rulemaking 06-04-09: Final opinion on greenhouse gas regulatory strategies, October 2008. http://docs.cpuc.ca.gov/.

[10] Y. Chen. Regional solution to a global problem: A short-run case analysis of co2 leakage and nox and so2 emissions spillovers. Energy Economics, 31:667-675, 2009.

[11] Y. Chen, P. Liu, and B.F. Hobbs. Economic and emissions implications of loadbased, source-based, and first-seller emissions programs under california ab32. Operations Research, Forthcoming -, 2010.

[12] R. W. Cottle, J.-S. Pang, and R. E. Stone. The Linear Complementarity Problem. Academic Press, Boston, 1992. 
[13] Damien Demailly and Philippe Quirion. Co2 abatement, competitiveness and leakage in the european cement industry under the eu ets: grandfathering versus outputbased allocation. Climate Policy, 6(1):93-113, 2006.

[14] S.P. Dirkse and M.C. Ferris. The path solver: a nommonotone stabilization scheme for mixed complementarity problems. Optimization Methods and Software, 5(2):123$156,1995$.

[15] A.D. Ellerman, P.L. Joskow, R. Schmalensee, J.P. Montero, and E. Bailey. Markets for clean air. Cambridge University Press New York, NY, 2000.

[16] C. Fischer. Market power and output-based refunding of environmental policy revenues. Resource and Energy Economics, Forthcoming:-, 2010.

[17] C. Fischer and A. K. Fox. Output-based allocation of emissions permits for mitigating tax and trade interactions. Land Economics, 83(4):575-599, 2007.

[18] D. Fullerton and G. Heutel. The general equilibrium incidence of environmental mandates. Working Paper 13645, National Bureau of Economic Research, November 2007.

[19] D. Fullerton and G. Metcalf. Environmental controls, scarcity rents, and pre-existing distortions. Journal of Public Economics, 80:249-267, 2001.

[20] M. Grubb and K. Neuhoff. Allocation and competitiveness in the eu emissions trading scheme: Policy overview. Climate Policy, 6(1):7-30, 2006.

[21] Western Climate Initiative. Design recommendations for the wci regional cap-andtrade program. Technical report, September 2008.

[22] J. Jensen and T.N. Rasmussen. Allocation of co2 emissions permits: A general equilibrium analysis of policy instruments. Journal of Environmental Economics and Management, 40:111-136, 2000.

[23] James Kanter and Jad Mouawad. Money and lobbyists hurt european efforts to curb gases. New York Times, December 102008.

[24] I. L. Goulder, I. Parry and D. Burtraw. Revenue-raising versus other approaches to environmental protection: The critical significance of preexisting tax distortions. RAND Journal of Economics, 28(4):708-731, 1997.

[25] Market Advisory Committee. Market Advisory Committee to the California Air Resources Board: Recommendation for designing a greenhouse gas cap-and-trade system for California, June 2007. 
[26] C. Metzler, B. Hobbs, and J.-S. Pang. Nash-Cournot equilibria in power markets on a linearized DC network with arbitrage: Formulations and properties. Networks 83 Spatial Economics, 3(2):123 - 150, 2003.

[27] Karsten Neuhoff, Kim Keats Martinez, and Misato Sato. Allocation, incentives and distortions: the impact of eu ets emissions allowance allocations to the electricity sector. Climate Policy, 6(1):73-91, 2006.

[28] J. Hughes S. Holland and C. Knittel. Greenhouse gas reductions under low carbon fuel standards? The American Economic Journal: Economic Policy, 1(1):106-146, 2008 .

[29] J. Shuliken, B. F. Hobbs, and J. S. Pang. Long-run equilibrium modeling of emissions allocation systems in electric power markets. Operations Research, forthcoming., 2009 .

[30] Thomas Sterner and Adrian Muller. Output and abatement effects of allocation readjustment in permit trade. Climatic Change, 86(1-2):33-49, January 2008. 